\title{
The Usability of ALOS-30m DEM for Flood Inundation Mapping in Data Sparse Regions: Sojasrood, Iran
}

\author{
Asghar Azizian* \\ Department of engineering and technology, Imam Khomeini International University, Iran
}

Submission: February 23, 2018; Published: May 04, 2018

"Corresponding author: Asghar Azizian, Department of engineering and technology, Imam Khomeini International University, Iran, Email: Azizian@Eng.ikiu.ac.ir

\begin{abstract}
The accuracy and quality of topographic datasets play an important role in deriving terrain model that is required for hydraulic simulation. Despite of several studies that have been carried out over the past decades it is still remained as a challenging issue for researchers, especially in developing countries and data limited areas. This study addresses the usability and efficiency of one of the newest remote sensing based DEMs, called ALOS-30m DEM, for flood inundation mapping in SojasRood river. Findings, indicate that the ALOS-30m dataset accurately captures the topographic details of river bed and the shape of cross-sections as well as topographic maps and this means that this valuable data source, in spite of having low resolution, have an appropriate potential of replacing the ground based DEMs. Moreover, assessing the predicted flood's components illustrate that using ALOS-30m dataset produces more accurate results when compared to contour based DEM. For instance, the maximum relative error in simulating mean WSE and inundated extent based on this dataset is lower than $13 \%$ and $8 \%$, respectively.
\end{abstract}

Keywords: Ground based DEM; ALOS-30m DEM; Flood inundation mapping; Remote sensing

\section{Introduction}

Hydraulic models are the best tools for simulation of flood and they provide predictions of flood extent and depth that are used in the development of spatially accurate hazard maps. In order to decrease the flood damages in rivers, identifying high flood risk areas by using these types of models is so necessary. Flood inundation mapping involves analysis of river flow data, hydrologic/hydraulic modelling and topographic surveys [1]. In flood inundation mapping studies, water surface elevation and flood extents play an important roles, especially in estimation of flood damages $[2,3]$. One of the most important variables that affects the accuracy of hydraulic models' outputs is the quantity and quality of topographic datasets or DEMs [1,4-7].

There are several studies that have been carried out to investigate the effects of DEM resolution and different topographic datasets on the performance of hydraulic models. For example, Werner et al. [8] analyzed the effect of DEM resolution on the accuracy of simulated flood areas and found that using coarser resolution DEM decrease the accuracy of hydraulic controls' elevations and flood extents, while using finer resolution DEM increase the computational time significantly. Haile et al. [9] investigated the sensitivity of 2D SOBEK flood model to DEM resolution (from $1 \mathrm{~m}$ to $15 \mathrm{~m}$ ) for an urban area in Honduras. Results showed that, because of averaging of small scale topographic features, DEM with the largest cell size simulated maximum inundated area. Casas et al. [10] Assessed the accuracy of different topographic sources in 1D hydraulic modeling for Ter River, Girona in NE Spain and concluded that the contour based dataset resulted the least accuracy in simulated flood areas, while LiDAR and GPS based datasets performed with the highest accuracy with less than 1 and $8 \%$ variation, respectively. Sanders et al. [11] Simulated flood extents in Santa Clara River in Texas by using four different DEM sources and showed that LiDAR DEMs, due to having the highest horizontal and vertical accuracy, are the best sources of terrain modeling and subsequently flood simulation. Schumann et al. [12] Demonstrated the effects of three DEMs at three different resolution from different data sources on deriving the water surface elevation and inundation area that simulated by using HEC-RAS 1D model. Findings indicated that although LiDAR and contour based DEMs resulted the lowest RMSE in deriving water surface elevation, but considering the performance of the SRTM DEM showed that this data set, despite of having coarser resolution, is a valuable source for flood simulation especially in large and homogenous areas. Patro et al. [13] selected an area in India to investigate the application of SRTM DEM with 90 meter resolution for extracting cross sections and hydraulic modelling. Findings revealed that the performance of hydraulic model was quite well, especially in simulating the peak flood value. Tarekegn et al. [14] evaluated the usefulness of ASTER DEM for flood simulation in a river in 
Ethiopia and concluded that the simulated flood inundated areas were in a good agreement with the observed flooding pattern. Azizian and Shokoohi $[15,16]$ addressed the effects of different DEM resampling methods on topographic index and the performance of TOPMODEL in Azarood river basin and found that Universal Kriging (UK) and Topo2Raster (T2R) methods are the best in simulating hydrograph peak flood. Ali et al. [3] assessed the impact of different DEM sources (SRTM, ASTER and LIDAR) on 1D hydraulic modeling of floods on a reach of the Johor River, in Malaysia. The outcomes showed that the loss of model accuracy due to resampling the fine resolution DEM to coarse resolution is much less than that of due to the use of low cost and low quality DEM.

In data sparse regions or developing countries, accessing to high resolution DEMs, such as LiDAR DEMs, isn't possible and ground based topographic maps should be provided. Moreover, the costs of ground surveying is one of the most limiting factor, especially in projects that suffer underfunding problems. Therefore, there must be an alternative topographic datasets for tackling or mitigating this problem. With the significant increase in human's technologies, the quality of remote sensing based DEMs is growing up so fast every day. One of the newest DEM sources is ALOS-30m resolution DEM that has been provided by the Japan Aerospace Exploration Agency (JAXA). Reviewing the literatures shows that there is no specific studies about the applicability and efficiency of this dataset for flood inundation mapping. So, the main objective of this study is to evaluate the performance and applicability of ALOS-30m DEM, free-public domain dataset, in flood inundation mapping and hydraulic simulation.

\section{Methods and Materials}

\section{Methodology}

To accomplish the objective mentioned earlier, the methodology includes the following steps:

1) providing ground based topographic map with the scale of 1:1000;

2) create DEM with 30 meter resolution;

3) collecting ALOS DEM with spatial resolution of 30 meter;

4) flood simulation and inundation mapping using 1D HEC-RAS and HEC-GeoRAS;

5) comparing the hydraulic features (flood extent and water surface elevation) that obtained from using both DEMs.

Study areaThe case study which is used in this research is SojasRood river, Zanjan province, Iran (Figure 1). The SojasRood River is located near the Gheidar city, and is surrounded by AghDagh mountainous and agricultural areas. The main channel of this river is V-shaped and surrounded by small trees and natural vegetation, which affect the flow moving between floodplain and main channel. Flood simulation for this river is performed by using 100 -year flow for steady state. The main reason that leads to selection of this return period is the flood inundation conditions in the large study reaches. Because in this reaches the floodplains do not get inundated for smaller return period flows. The quality of 30 meter DEM resolution that obtained using both ground based dataset and ALOS source, is shown in Figure 2.

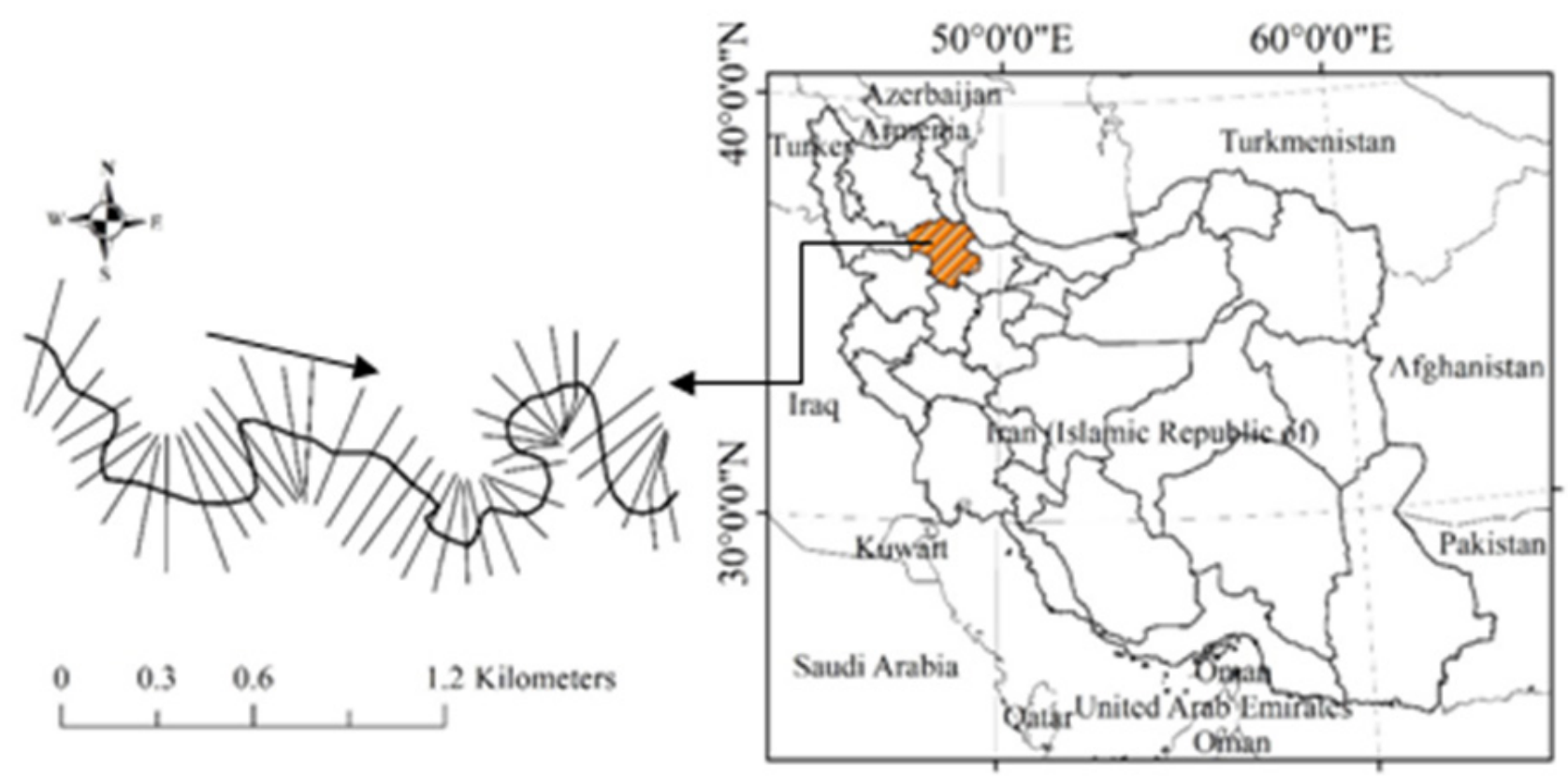

Figure 1: Layout Map of the Study Areas. 

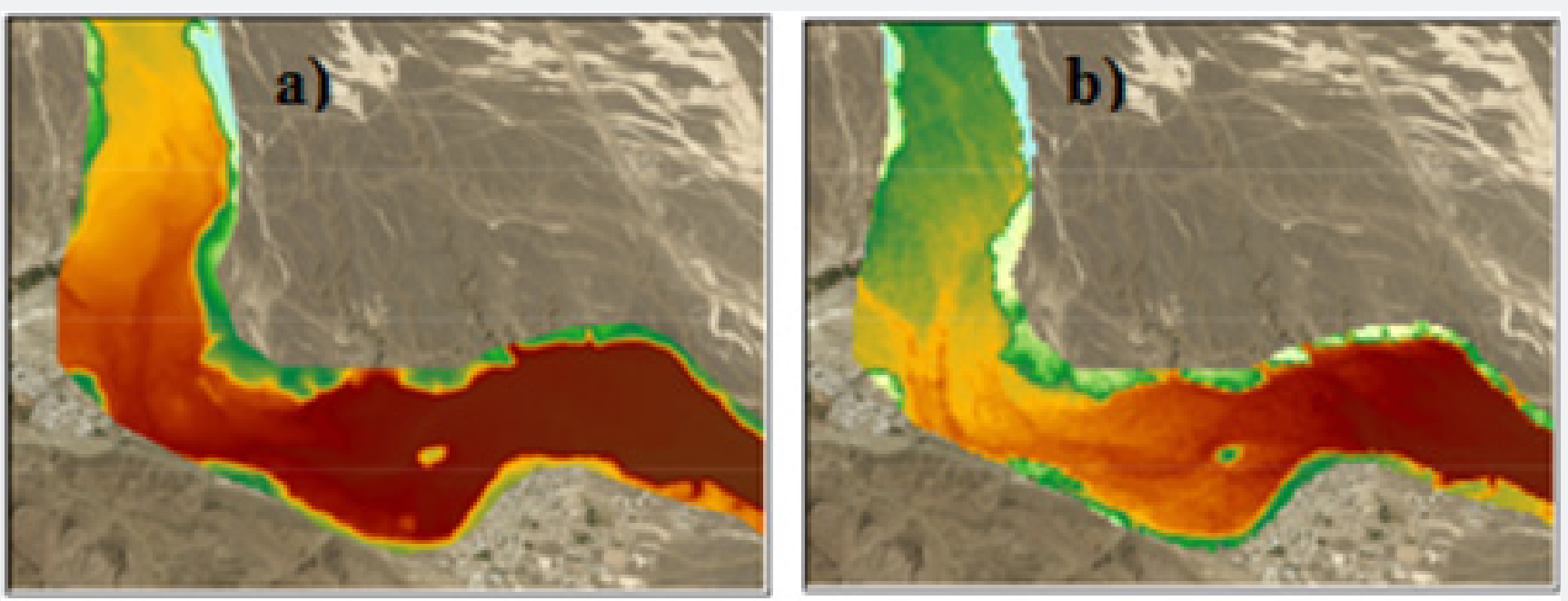

Figure 2: DEMs used in SojasRood river (a) contour based DEM and (b) ALSO 30m DEM.

Results

\section{The accuracy of ALOS-30m DEM in deriving cross- sections}

Comparing the terrain model obtained from ground based DEM, as a base model, and ALOS-30m DEM shows that there is a good agreement between them. Accurately presenting the topographic features of river bed is one the most important factors that increases the similarity between this dataset and ground based DEM. The efficiency of this DEM source in deriving the shape of cross-section versus ground based DEM is shown in Figure 3. As it can be clearly seen, ALOS-30m DEM accurately capture the shape of cross-sections and river bed elevations as well as topographic map. In other words, ALOS-30m DEM is an appropriate alternative for ground based DEMs, especially in data limited regions [17-26].
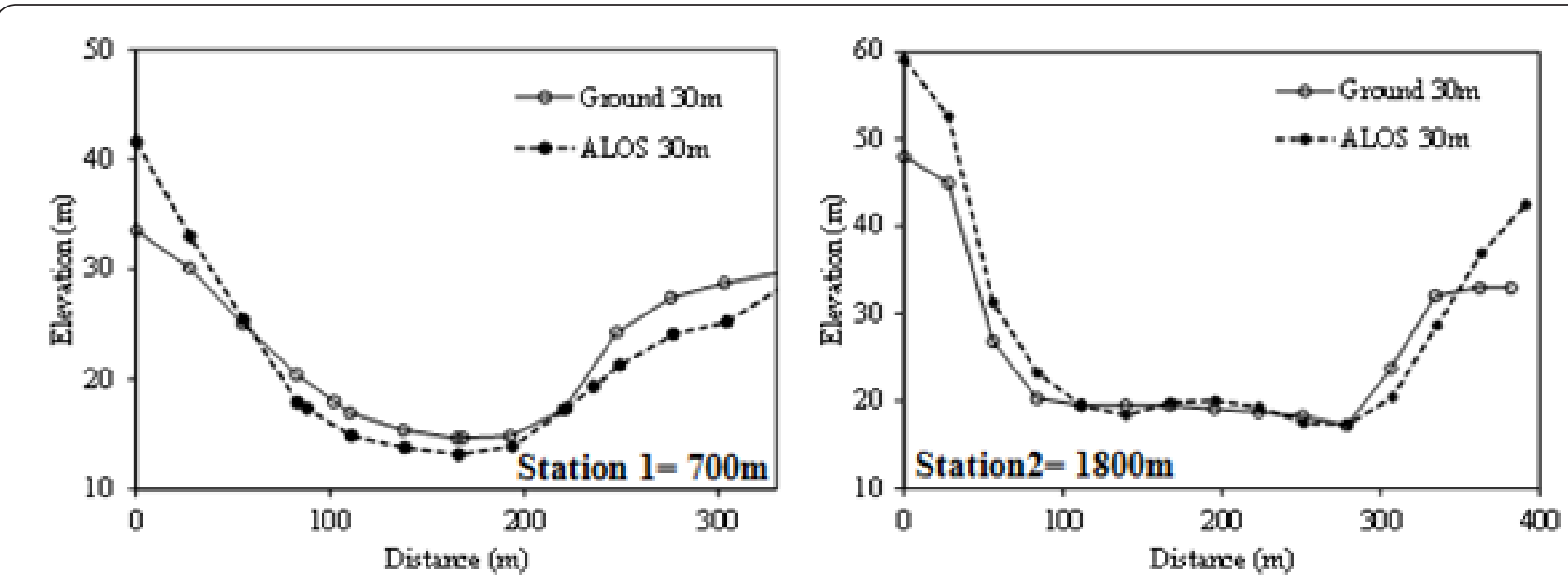

Figure 3: Comparison of ALOS-30m DEM and ground based DEM in deriving cross-section's shape.

\section{Efficiency of ALOS-30m DEM for hydraulic simulation}

Findings on flood simulation reveal that hydraulic modeling and flood inundation mapping using ALOS-30m dataset produces more accurate results when compared to ground-based DEM. For example, using this dataset in SojasRood river results averagely $13.4 \%$ and $7.6 \%$ relative errors in simulating inundated extent and water surface elevation (WSE) (Figure 4). Results show that by using ALOS-30m DEM the relative error of inundated extent in $90 \%$ of cross-sections is lower than $15 \%$. In addition, if the value of $\pm 10 \%$ is used as a reasonable relative error range, the performance of HEC-RAS model in more than $78 \%$ of crosssections obtained from ALOS-30 will be acceptable. 


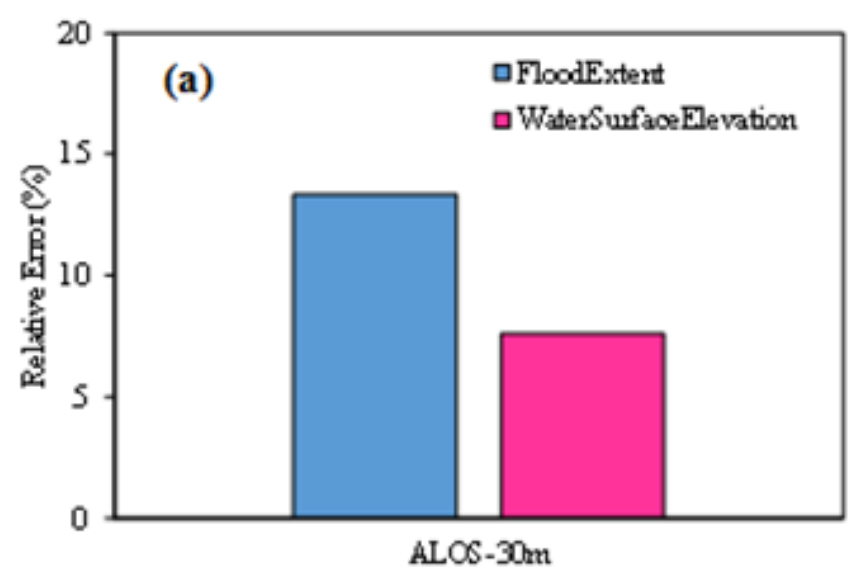

Figure 4: Average relative error of flood components (Top Width and WSE) in SojasRood river.

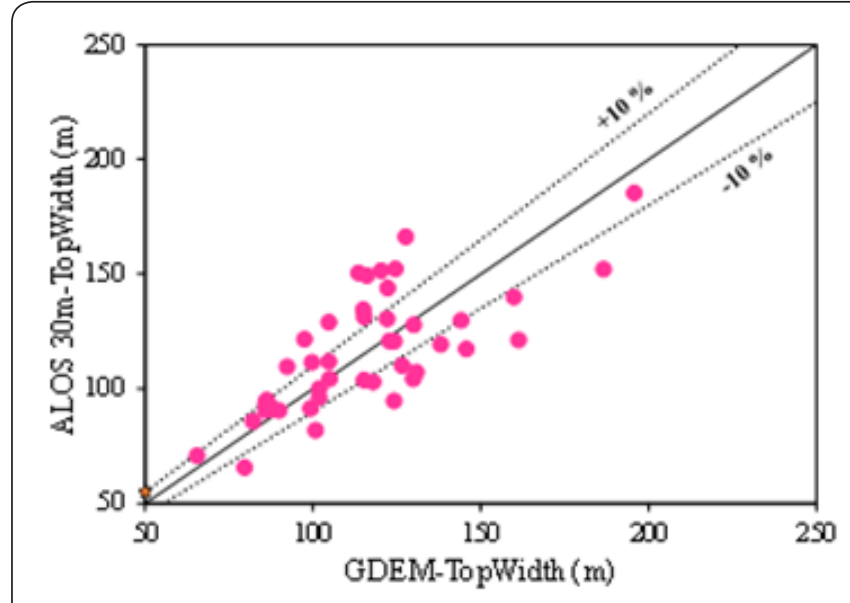

Figure 5: The performance of ALOS-30m DEM vs ground based DEM in simulating flood inundated extent.

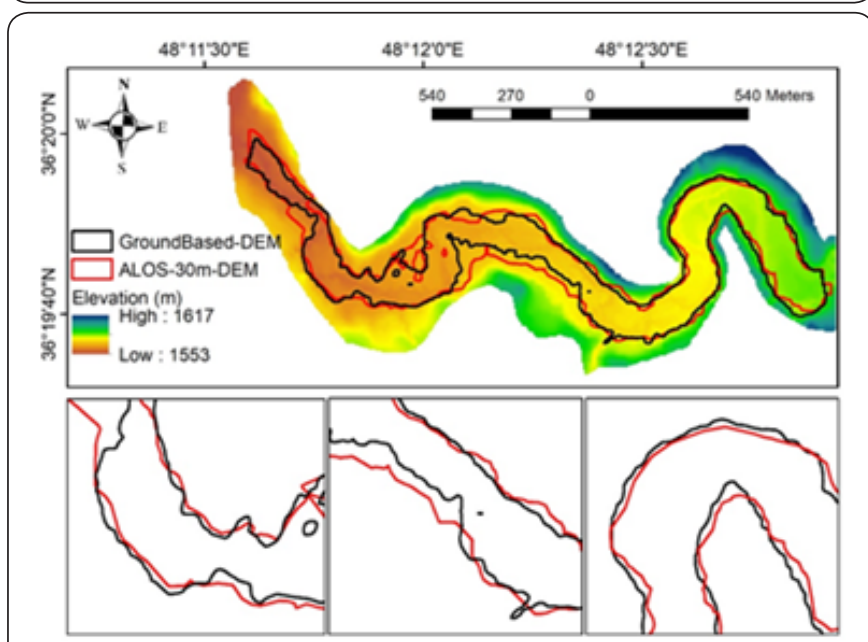

Figure 6: Spatial pattern of flood extent in ALOS-30m and ground based DEMs.

Finally, for better assessing the performance of ALOS-30m DEM in flood simulation, the results of hydraulic simulation in each cross-section compared with that of in ground based DEM with 30 meter resolution's result (Figure 5). As mentioned, in this research the error band width of $\pm 10 \%$ in simulating inundated extent accepted as a reasonable range for evaluating the usability of ALOS-30m DEM. The results clearly prove that using ALOS-30m DEM leads to better performance almost in most cross-sections and can be considered as the best alternative for topographic maps Moreover, the spatial pattern of inundated extent in SojasRood river (Figure 6) completely prove the advantages of ALOS-30m DEM.

\section{Conclusion}

The accuracy and quality of topographic datasets play an important role in deriving terrain model that are required for hydraulic simulation. Despite of several studies that have been carried out over the past decades it is still remained as a challenging issue for researchers, especially in developing countries and data limited areas. This study addresses the usability and efficiency of one of the newest remote sensing based DEMs, called ALOS-30m DEM, for flood inundation mapping in SojasRood River. Findings indicate that the ALOS$30 \mathrm{~m}$ dataset accurately captures the topographic details of river bed and the shape of cross-sections as well as topographic maps and this means that this valuable data source, in spite of having low resolution, have an appropriate potential of replacing the ground based DEMs. Moreover, assessing the predicted flood's components illustrate that using ALOS-30m dataset produces more accurate results when compared to contour based DEM. For instance, the maximum relative error in simulating mean WSE and inundated extent based on this dataset is lower than 13 $\%$ and $8 \%$, respectively.

\section{References}

1. Saksena S, Merwade V (2015) Incorporating the effect of DEM resolution and accuracy for improved flood inundation mapping. J. Hydrol 530: 180-194.

2. Cook A, Merwade V (2009) Effect of topographic data, geometric configuration and modeling approach on flood inundation mapping. J. Hydrol 377(1-2): 131-142.

3. Ali AM, Solomatine DP, Baldassarre GD (2015) Assessing the impact of different sources of topographic data on 1-D hydraulic modelling of floods. Hydrol. Earth Syst. Sci 19: 631-643.

4. Hall JW, Tarantola S, Bates PD, Horritt MS (2005) Distributed sensitivity analysis of flood inundation model calibration. J. Hydraulic. Eng. 131 (2): 117-126. 
5. Pappenberger F, Matgen P, Beven KJ, Henry JB, Pfister L, et al. (2006) Influence of uncertain boundary conditions and model structure on flood inundation predictions. Adv. Water Resour 29(10): 1430-1449.

6. Jung Y, Merwade V (2011) Uncertainty quantification in flood inundation mapping using generalized likelihood uncertainty estimate and sensitivity analysis. J Hydrol Eng 17(4): 507-520.

7. Lin S, Jing C, Coles NA, Chaplot V, Moore NJ, et al. (2012) Evaluating DEM source and resolution uncertainties in the soil and water assessment tool. Stoch Env Res Risk Assess 27(1): 209-221.

8. Werner MGF (2001) Impact of grid size in GIS based flood extent mapping using 1-D flow model. Phys Chem Earth (B). 26(7-8): 517 522.

9. Haile A, Rientjes T (2005) Effects of Li DAR DEM Resolution in Flood Modelling: A Model Sensitivity Study for the City of Tegucigalpa, Honduras. ISPRS WGIII/3,III/4V/3 Workshop "Laser Scanning 2005" pp. 168-173.

10. Casas A, Benito G, Thorndycraft VR, Rico M (2006) The topographic data source of digital terrain models as a key element in the accuracy of hydraulic flood modelling. Earth Surf Proc Land 31(4): 444-456.

11. Sanders BF (2007) Evaluation of on-line DEMs for flood inundation modelling. Adv Water Resour 30(8): 1831-1843.

12. Schumann G, Matgen P, Cutler MEJ, Black A, Hoffmann L, et al. (2008) Comparison of remotely sensed water stages from LiDAR, topographic contours and SRTM. ISPRS J Photogramm Remote Sens 63(3): 283-296

13. Patro S, Chatterjee C, Singh R, Raghuwanshi NS (2009) Hydrodynamic modelling of a large flood-prone system in India with limited data. Hydrol Process 23(19): 2774-2791.

14. US Army Corps of Engineers (2010) HEC-RAS River Analysis System Hydraulic Reference Manual. Version 4.1. Hydrologic Engineering Center, Davis, California pp.411.

15. Azizian A, Shokoohi AR (2015) Investigation of the Effects of DEM Creation Methods on the Performance of a Semi distributed Model: TOPMODEL. J Hydro Eng 20(11): 1-9.
16. Azizian A, Shokoohi AR (2015) Effects of Data resolution and stream delineation threshold effects on the results of a Kinematic Wave based GIUH model. Journal of Water SA 41(9): 61-70.

17. Azizian A, Shokoohi AR (2014) DEM resolution and stream delineation threshold effects on the results of geomorphologic-based rainfall runoff models. Turkish J Eng Env Sci 38(1): 64-78.

18. Brandt S (2005) Resolution issues of elevation data during inundation modeling of river floods. In: Proceedings of the XXXI International Association of Hydraulic Engineering and Research Congress (IAHR) pp. 3573-3581.

19. Bruner GW (2014) Combined 1D and 2D Modeling with HEC-RAS. Version 5 Hydrologic Engineering Center, Davis, California pp. 130.

20. Laks I, Sojka M, Walczak Z, Wrózynski R (2017) Possibilities of Using Low Quality Digital Elevation Models of Floodplains in Hydraulic Numerical Models. Water 9(4): 283-300.

21. Kavanagh BF, Glenn Bird SJ (1996) Surveying principles and applications ( $4^{\text {th }}$ edn) Prentice Hall pp. 257-264.

22. Quiroga M, Popescu V, Solomatine I, Bociort L (2013) Cloud and cluster computing in uncertainty analysis of integrated flood models. J Hydroinf 15(1): 55-69.

23. Tarekegn TH, Haile AT, Rientjes T, Reggiani P, Alkema D (2010) Assessment of an ASTER generated DEM for 2D flood modelling. Int J Appl Earth Obs Geoinf 12(6): 457-465.

24. U.S. Army Corps of Engineers (2016). HEC-RAS River Analysis System 2D Modeling User's Manual. Version 5.0. Hydrologic Engineering Center, Davis, California pp.171.

25. Vaze J, Teng J, Spencer G (2010) Impact of DEM accuracy and resolution on topographic indices. Environ Model Softw 25(10): 1086-1098.

26. Wilson MD, Atkinson PM (2005) The use of elevation data in flood inundation modelling: a comparison of ERS interferometric SAR and combined contour and differential GPS data. Intl. J. River Basin Management 3(1): 3-20.

\section{Your next submission with Juniper Publishers will reach you the below assets}

- Quality Editorial service

- Swift Peer Review

- Reprints availability

- E-prints Service

- Manuscript Podcast for convenient understanding

- Global attainment for your research

- Manuscript accessibility in different formats

( Pdf, E-pub, Full Text, Audio)

- Unceasing customer service

Track the below URL for one-step submission https://juniperpublishers.com/online-submission.php 